\title{
Determination of oxygen adsorption-desorption rates and diffusion rate coefficients in perovskites at different oxygen partial pressures by a microkinetic approach
}

\author{
M. Rochoux, Y. Guo, Y. Schuurman and D. Farrusseng*
}

\begin{abstract}
A novel, powerful method based on a microkinetic approach is described for the estimation of the oxygen transport parameters of mixed electronic conducting materials (MIECs). This method is validated on the perovskite $\mathrm{La}_{0.6} \mathrm{Sr}_{0.4} \mathrm{Co}_{0.2} \mathrm{Fe}_{0.8} \mathrm{O}_{3-\delta}$ and has been applied on $\mathrm{Ba}_{0.5} \mathrm{Sr}_{0.5} \mathrm{CO}_{0.8} \mathrm{Fe}_{0.2} \mathrm{O}_{3-\delta}$. This approach is original and relevant in that the surface kinetic rate constants are measured using a sample in powder form. In contrast to methods previously used, such as isotope exchange depth profiling (IEDP) and electrical conductivity relaxation (ECR), which determine the global exchange kinetic parameter, our microkinetic modelling approach allows the estimation of the forward and reverse kinetic rates accounting for the oxygen vacancy concentration. Also, the self-diffusion rate coefficient has been estimated at different oxygen partial pressures. This microkinetic approach, which combines SSITKA (steady-state isotopic transient kinetic analysis) and thermogravimetric measurements at controlled oxygen partial pressure, has the potential to significantly accelerate the characterization of oxygen transport in perovskites and related materials in the future. In this study, the kinetic parameters were measured in a temperature window between $873 \mathrm{~K}$ and $1173 \mathrm{~K}$, and at two oxygen pressure conditions ( $21 \mathrm{kPa}$ and $1 \mathrm{kPa}$ ) that are appropriate for simulating the semipermeability of oxygen in a membrane in a process of oxygen separation from air.
\end{abstract}

\section{Introduction}

Mixed ionic and electronic conductors (MIECs) are an important class of materials that include oxides of different structures such as perovskites, brownmillerite and fluorites. They can potentially be employed in high-temperature applications for which simultaneous reaction and separation is advantageous. ${ }^{1}$ Research using MIECs has been conducted on partial oxidation of methane to syngas, ${ }^{2,3}$ oxidative coupling of methane, ${ }^{4}$ and oxidative dehydrogenation of ethane to ethylene. ${ }^{5}$ These materials are also proposed for oxygen separation applications and cathode materials for the latest SOFC technologies. ${ }^{6-10}$

IRCELYON, Université Lyon 1, CNRS - 2, Avenue Albert Einstein, F-69626 Villeurbanne, France.E-mail: david.farrusseng@ircelyon.univ-lyon1.fr $\dagger$ Electronic supplementary information (ESI) available: (1) XRD after crushing; (2) solid density; (3) SSITKA experimental bench; (4) determination of the type of oxygen isotopic exchange; (5) determination of the variation of the quantity of vacancies from TGA experiments; (6) impact of a dwell on the TGA signal; (7) stability of the perovskite before and after TGA; (8) determination of the Langmuir parameters; (9) correlation of the parameters; (10) $V_{\mathrm{m}}$ calculation from mesh parameter obtained through in situ XRD experiments. See DOI: 10.1039/ c4cp04243c
The mechanism of oxygen transport through these materials can be summarized in three major steps. The first step is the dissociative adsorption of $\mathrm{O}_{2}$ on the surface of the perovskite, leading to the formation of anionic oxygen; the second step is oxygen diffusion by an activated hopping mechanism with oxygen vacancies $\left(\mathrm{V}_{\mathrm{O}, \mathrm{s}}^{\bullet \bullet}\right)$; and the final step is the desorption/ recombination of $\mathrm{O}_{2}$ on the permeate side. ${ }^{11}$ Different experimental techniques and associated modelling approaches have been developed for the measurement and estimation of the surface exchange parameters and diffusion parameters that govern the oxygen flux in MIEC membranes in general and perovskite membranes in particular.

$\mathrm{Xu}$ and Thomson ${ }^{12}$ developed a membrane transport model that enables the determination of the forward and reverse adsorption kinetics and the diffusion parameter of membrane materials using a dataset of semi-permeability measurements. The model is based on the following assumptions: the forward and reverse parameters for the equations, $k_{\mathrm{f}}$ and $k_{\mathrm{r}}$, are assumed to be independent of the oxygen partial pressure, and to be equal on both membrane interfaces.

$$
1 / 2 \mathrm{O}_{2}+\mathrm{V}_{\mathrm{O}, \mathrm{S}}^{\bullet \bullet} \stackrel{k_{\mathrm{f}}}{\longrightarrow} \mathrm{O}_{\mathrm{O}, \mathrm{s}}^{\times}+2 \mathrm{~h}^{\bullet}
$$




$$
\mathrm{O}_{\mathrm{O}, \mathrm{s}}^{\times}+2 \mathrm{~h}^{\bullet} \stackrel{k_{\mathrm{r}}}{\longrightarrow} 1 / 2 \mathrm{O}_{2}+\mathrm{V}_{\mathrm{O}, \mathrm{S}}^{\bullet \bullet}
$$

The diffusion of oxygen in the bulk $\left(\mathrm{O}_{\mathrm{O}, \mathrm{s}}^{\times}\right)$is described by Fick's first law. Although the diffusion parameter $\left(D_{\mathrm{v}}\right)$ depends in theory on the oxygen defect lattice structure, ${ }^{13} \mathrm{Xu}$ and Thomson assume $D_{\mathrm{v}}$ to be constant across the membrane despite the different oxygen potential, and the number of oxygen vacancies $\left(\mathrm{V}_{\mathrm{O}, \mathrm{s}}^{\bullet \bullet}\right)$. From the assumptions that the kinetic parameters $k_{\mathrm{r}}, k_{\mathrm{f}}$ and $D_{\mathrm{v}}$ are constants regarding oxygen potential, $\mathrm{Xu}$ and Thomson arrive at the following expression for the oxygen flux across a thin ceramic membrane:

$$
J_{\mathrm{O}_{2}}=\frac{D_{\mathrm{v}} k_{\mathrm{r}}\left(P_{\mathrm{O}_{2}}^{\prime 0.5}-P_{\mathrm{O}_{2}}^{\prime \prime 0.5}\right)}{2 L k_{\mathrm{f}}\left(P_{\mathrm{O}_{2}}^{\prime} P_{\mathrm{O}_{2}}^{\prime \prime}\right)^{0.5}+D_{\mathrm{v}}\left(P_{\mathrm{O}_{2}}^{\prime 0.5}+P_{\mathrm{O}_{2}}^{\prime \prime 0.5}\right)}
$$

The six parameters of expression (3) accounting for the preexponential factors of the diffusion, forward reaction and reverse reaction $\left(D_{\mathrm{v}}^{\circ}, k_{\mathrm{f}}^{\circ}, k_{\mathrm{r}}^{\circ}\right)$, and associated activation energy $\left(E_{\mathrm{d}}, E_{\mathrm{f}}, E_{\mathrm{r}}\right)$ were estimated by regression on two distinct $\mathrm{La}_{0.6} \mathrm{Sr}_{0.4} \mathrm{Co}_{0.2} \mathrm{Fe}_{0.8} \mathrm{O}_{3-\delta}$ membranes of different thicknesses and using 126 different experimental conditions of oxygen partial pressure and temperature.

The measurement of oxygen semi-permeability on membranes, along with modelling using the $\mathrm{Xu}$ and Thomson model, is currently the only solution for the estimation of both forward and backward kinetic parameters for oxygen adsorptiondesorption on MIEC materials. Other characterization techniques such as electrical conductivity relaxation (ECR) $)^{14-16}$ and isotopic exchange depth profiling (IEDP), ${ }^{17-19}$ which are carried out on shaped materials, give access to global kinetic rate parameters only. Hence, there is a strong incentive to develop straightforward approaches that do not involve membrane testing under relevant (steady-state) conditions for the measurement of microkinetic constants.

In this paper, we describe an original methodology based on measurements on perovskites in powder form, for the microkinetic modelling of oxygen transport under conditions applied during membrane operation. The originality of our method consists in the integration of oxygen vacancy concentration measurements by thermogravimetric analysis (TGA) with isotopic oxygen exchange experiments $\left({ }^{16} \mathrm{O}_{2} /{ }^{18} \mathrm{O}_{2}\right)$ in a microkinetic model. All necessary kinetic and transport parameters can be estimated and used as input for an oxygen membrane flux model in order to optimize the material formulation. Our novel microkinetic approach is validated on $\mathrm{La}_{0.6} \mathrm{Sr}_{0.4} \mathrm{Co}_{0.2} \mathrm{Fe}_{0.8} \mathrm{O}_{3-\delta}$ (LSCF) by comparing results obtained by the $\mathrm{Xu}$-Thomson approach and then applied on $\mathrm{Ba}_{0.5} \mathrm{Sr}_{0.5} \mathrm{Co}_{0.8} \mathrm{Fe}_{0.2} \mathrm{O}_{3-\delta}$ (BSCF), which is currently the most-studied perovskites in the domain. ${ }^{10}$ The result section is divided into three parts: (i) determination of the adsorption equilibrium constant $(K)$ and the degree of oxygen non-stoichiometry $(\delta)$ from TGA experiments, (ii) estimation of kinetic rate parameters $\left(k_{\mathrm{f}}, k_{\mathrm{r}}\right)$ from oxygen isotopic exchange experiments, and (iii) estimation of the oxygen self-diffusion rate $\left(D^{*}\right)$.

\section{Experimental}

\section{Perovskite synthesis and characterization}

$\mathrm{La}_{0.6} \mathrm{Sr}_{0.4} \mathrm{Co}_{0.2} \mathrm{Fe}_{0.8} \mathrm{O}_{3-\delta}$ (LSCF) was synthesized using a sol gel method. All the precursors were purchased from Sigma Aldrich (pur: 99.5\%). $\quad \mathrm{La}\left(\mathrm{NO}_{3}\right)_{3} \cdot 6 \mathrm{H}_{2} \mathrm{O}\left(433.01 \mathrm{~g} \quad \mathrm{~mol}^{-1}\right), \quad \operatorname{Sr}\left(\mathrm{NO}_{3}\right)_{2}$ $\left(211.6 \mathrm{~g} \mathrm{~mol}^{-1}\right), \mathrm{Fe}\left(\mathrm{NO}_{3}\right)_{3} \cdot 9 \mathrm{H}_{2} \mathrm{O}\left(404.0 \mathrm{~g} \mathrm{~mol}^{-1}\right)$ and finally $\mathrm{Co}\left(\mathrm{NO}_{3}\right)_{2} \cdot 6 \mathrm{H}_{2} \mathrm{O}\left(291.0 \mathrm{~g} \mathrm{~mol}{ }^{-1}\right)$. These components were weighed and then stirred in distilled water until total dissolution of the components. Meanwhile, ethylenediaminetetraacetic acid (EDTA, $292.24 \mathrm{~g} \mathrm{~mol}^{-1}$ ) and citric acid (192.1 $\mathrm{g} \mathrm{mol}^{-1}$ ) were mixed in distilled water. One molar equivalent of EDTA was added for each molar equivalent of total metal ion and two molar equivalent of citric acid. This mixture was stirred until total dissolution of both components. Ammonia solution was then slowly added until a transparent solution was obtained $(70 \mathrm{~mL}, 6<\mathrm{pH}<8)$. The solution was stirred and heated at $373 \mathrm{~K}$ until a gel like solution was obtained. The resulting gel was heated at $473 \mathrm{~K}$ in air for two hours and then fired for 5 hours at $1423 \mathrm{~K}$ in order to obtain a pure perovskite phase.

$\mathrm{Ba}_{0.5} \mathrm{Sr}_{0.5} \mathrm{Co}_{0.8} \mathrm{Fe}_{0.2} \mathrm{O}_{3-\delta}$ (BSCF) powder was purchased from Marion Technologies (France). The perovskite powder was processed in the same manner as for membrane preparation in order to generate an identical microstructure. The powder was dry-pressed at a pressure of $100 \mathrm{MPa}$. After sintering at $1448 \mathrm{~K}$ for $10 \mathrm{~h}$, the relative density of the pellet was about 86-91\%. The resulting sintered pellet was gently crushed and sieved at the $425-600 \mu \mathrm{m}$ fraction for TGA, SSITKA and scanning electron microscopy (SEM) studies. The structure of a crushed powder was analyzed by X-ray diffraction (XRD) at room temperature in air using a Bruker D8 Advance A25 system in the $2 \Theta$ range of $3-80^{\circ}$, with a step width of $0.02^{\circ}$, a counting time of $1 \mathrm{~s}$ and $\mathrm{Cu} \mathrm{K} \alpha 1+\alpha 2$ radiation $(\lambda=1.54184 \AA)($ ESI- $1 \dagger)$. The solid density of LSCF and BSCF was calculated from the unit cell parameters at room temperature (ESI-2 $\dagger$ ). The crystallite size distribution was determined from SEM images (ImageJ software) using a spherical model on a population of 250 crystallites. Independently, the porous oxide powder is modelled using the equivalent geometry of dense sphere given by $d_{\text {crys }}=$ $6 /\left(\rho \times S_{\mathrm{BET}}\right){ }^{20,21}$ The specific surface areas $\left(S_{\mathrm{BET}}\right)$ are measured by nitrogen adsorption at $77 \mathrm{~K}$.

\section{Steady-state isotopic transient kinetic analysis (SSITKA)}

The oxygen exchange experiments were carried out in a fixedbed quartz tube reactor (i.d. $5 \mathrm{~mm}$ ) containing $50 \mathrm{mg}$ of sieved perovskite (ESI- $3 \dagger)$. The reactor space before the sample was filled with quartz particles of the same sieve fraction. This lowers the dead volume, preheats the gas, and establishes a plug flow before the sample. A thermocouple was inserted directly into the sample zone to monitor the sample temperature. Experiments were carried out from $873 \mathrm{~K}$ to $1173 \mathrm{~K}$ with a step every $50 \mathrm{~K}$ and at a pressure between 120 and $160 \mathrm{kPa}$. Inlet flows were controlled using mass flow controllers. A gas mixture of $50 \mathrm{~mL} \mathrm{~min}{ }^{-1}$ of $x \%{ }^{16} \mathrm{O}_{2}$ (Air Liquide, 99.999\%) + $(100-x) \%$ Ar was replaced by a mixture of $50 \mathrm{~mL} \min ^{-1}$ of $x \%$ ${ }^{18} \mathrm{O}_{2}$ (Eurisotop $98 \%{ }^{18} \mathrm{O}_{2}$ and $\left.2 \%{ }^{16} \mathrm{O}_{2}\right)+5 \% \mathrm{~N}_{2}+(95-x) \% \mathrm{Ar}$, 
where $x$ was either $21 \%$ or $1 \%$. After this experiment, a backswitch was performed. The changes in the gas composition were continuously monitored using a mass spectrometer $(\mathrm{m} / \mathrm{z}=$ $32,34,36,40$ and 28) with an acquisition rate of approximately 1 point per s. Nitrogen was added to the feed gas as an inert tracer to measure the gas holdup of the system. The highest oxygen exchange rate was measured at $900{ }^{\circ} \mathrm{C}$ and amounted to $1.5 \times 10^{-4} \mathrm{~mol} \mathrm{~kg}^{-1} \mathrm{~s}^{-1}$. Under these conditions, the Carberry number, which characterizes external diffusion limitations, amounts to $2 \times 10^{-6}$. This is well below the value of 0.05 at which diffusion limitations may occur. Similarly, the Weisz modulus of $10^{-5}$ is well below the critical value of 0.08 for pore diffusion limitations. ${ }^{22}$

\section{Thermogravimetric analysis (TGA)}

The degree of oxygen non-stoichiometry $(\delta)$ of the perovskite was measured as a function of temperature using a Setsys Evolution 12 thermogravimetric analyzer from SETARAM. The measurements were carried out on $80 \mathrm{mg}$ of sample under a total flow of $50 \mathrm{~mL} \mathrm{~min}^{-1}$ consisting of argon and two different partial pressures of oxygen, $P_{\mathrm{O}_{2}}=21 \mathrm{kPa}$ and $1 \mathrm{kPa}$. Two different temperature programs were carried out, a continuous ramp and step-by-step to target settings for method validation purposes. For the continuous ramp, the temperature was increased from room temperature up to $1173 \mathrm{~K}$ with a heating ramp of $5 \mathrm{~K} \mathrm{~min}^{-1}$. The stepwise program consisted of twohour dwells at constant temperature that allowed the sample to reach thermodynamic equilibrium. Prior to analysis, the sample was pre-treated in situ in an oxygen-helium mixture for two hours at $1173 \mathrm{~K}$ in order to remove all traces of water and carbonates. It was then cooled down to room temperature in a $\mathrm{CO}_{2}$ - and water-free atmosphere. The structure of the perovskite was checked by XRD after TG analysis. The initial oxygen non-stoichiometry $(\delta)$ of $\mathrm{La}_{0.6} \mathrm{Sr}_{0.4} \mathrm{Co}_{0.2} \mathrm{Fe}_{0.8} \mathrm{O}_{3-\delta}$ and $\mathrm{Ba}_{0.5} \mathrm{Sr}_{0.5} \mathrm{Co}_{0.8} \mathrm{Fe}_{0.2} \mathrm{O}_{3-\delta}$ was measured by iodometric titration using a state of the art method which is described elsewhere by Manthiram et al. ${ }^{23}$

\section{Isotopic oxygen exchange modelling}

\section{Microkinetic model}

Oxygen exchange between gas-phase oxygen and solid oxides such as perovskites can occur according to three overall reactions in which zero, one, or two oxygen atoms are exchanged with the solid. ${ }^{24-27}$ Based on the best fit, model discrimination was carried out in order to select the most appropriate exchange model (ESI-4 $\dagger$ ). A double hetero-exchange was assumed and is described by the following equations:

$$
\begin{gathered}
{ }^{18} \mathrm{O}_{2}+2{ }^{16} \mathrm{O}_{\mathrm{O}, \mathrm{s}}^{\times} \stackrel{k_{1} / k_{-1}}{\rightleftharpoons}{ }^{16} \mathrm{O}_{2}+2{ }^{18} \mathrm{O}_{\mathrm{O}, \mathrm{s}}^{\times} \\
{ }^{16} \mathrm{O}^{18} \mathrm{O}+2{ }^{16} \mathrm{O}_{\mathrm{O}, \mathrm{s}}^{\times} \stackrel{k_{1} / k_{-1}}{\rightleftharpoons}{ }^{16} \mathrm{O}_{2}+{ }^{18} \mathrm{O}_{\mathrm{O}, \mathrm{s}}^{\times}+{ }^{16} \mathrm{O}_{\mathrm{O}, \mathrm{s}}^{\times} \\
{ }^{16} \mathrm{O}^{18} \mathrm{O}+2{ }^{18} \mathrm{O}_{\mathrm{O}, \mathrm{s}}^{\times} \stackrel{k_{1} / k_{-1}}{\rightleftharpoons}{ }^{18} \mathrm{O}_{2}+{ }^{18} \mathrm{O}_{\mathrm{O}, \mathrm{s}}^{\times}+{ }^{16} \mathrm{O}_{\mathrm{O}, \mathrm{s}}^{\times}
\end{gathered}
$$

The proposed microkinetic model involves the integration of oxygen vacancies $\left(\mathrm{V}_{\mathrm{O}}^{\bullet \bullet}\right)$ in the description of oxygen adsorption-desorption at the surface. Eqn (7) and (8) are the corresponding elementary steps for eqn (4).

$$
\begin{aligned}
& { }^{18} \mathrm{O}_{2}+2 \mathrm{~V}_{\mathrm{O}, \mathrm{s}}^{\bullet \bullet} \stackrel{k_{\mathrm{f} 1} / k_{\mathrm{r} 1}}{\rightleftharpoons} 2^{18} \mathrm{O}_{\mathrm{O}, \mathrm{s}}^{\times}+4 \mathrm{~h}^{\bullet} \\
& 2^{16} \mathrm{O}_{\mathrm{O}, \mathrm{s}}^{\times}+4 \mathrm{~h} \stackrel{k_{\mathrm{r} 2} / k_{\mathrm{f} 2}}{\rightleftharpoons}{ }^{16} \mathrm{O}_{2}+2 \mathrm{~V}_{\mathrm{O}, \mathrm{s}}^{\bullet \bullet}
\end{aligned}
$$

The rate constants in eqn (7) and (8) are the same because the kinetic isotope effect between ${ }^{18} \mathrm{O}_{2}$ and ${ }^{16} \mathrm{O}_{2}$ is negligible under these conditions. Therefore, $k_{\mathrm{f} 1}=k_{\mathrm{f} 2}=k_{\mathrm{f}}$ and $k_{\mathrm{r}}=k_{\mathrm{r} 1}=k_{\mathrm{r} 2}$. The kinetic constants $k_{\mathrm{f}}$ and $k_{\mathrm{r}}$ are expressed in the units of $\mathrm{Pa}^{-1} \mathrm{~s}^{-1}$ and $\mathrm{s}^{-1}$, respectively, with $E_{\mathrm{f}}$ and $E_{\mathrm{r}}$ being the associated activation energies in $\mathrm{kJ} \mathrm{mol}^{-1}$.

$$
\begin{aligned}
& k_{\mathrm{r}}=k_{\mathrm{r}}^{\circ} \exp \left(\frac{-E_{\mathrm{r}}}{R T}\right) \\
& k_{\mathrm{f}}=k_{\mathrm{f}}^{\circ} \exp \left(\frac{-E_{\mathrm{f}}}{R T}\right)
\end{aligned}
$$

The reaction rate $(r)$ for this step according to the law of mass action then reads:

$$
\begin{aligned}
& r=k_{\mathrm{f}} P_{{ }_{18} \mathrm{O}_{2}} \theta_{\mathrm{v}}{ }^{2}-k_{\mathrm{r}} \theta_{18}^{2} \mathrm{O} h^{4} \\
& r=k_{\mathrm{r}} \theta_{{ }^{2} \mathrm{O}}^{2} h^{4}-k_{\mathrm{f}} P_{{ }^{16} \mathrm{O}_{2}} \theta_{\mathrm{v}}^{2}
\end{aligned}
$$

To complete the oxygen exchange kinetics, a third rate equation for $P_{16_{\mathrm{O}} 18_{\mathrm{O}}}$ is necessary:

$$
r=k_{\mathrm{f}} P_{18_{\mathrm{o}} 16_{\mathrm{o}}} \theta_{\mathrm{v}}{ }^{2}-k_{\mathrm{r}} \theta_{18_{\mathrm{o}}} \theta_{16_{\mathrm{o}}} h^{4}
$$

The total oxygen coverage gives $\theta_{16_{\mathrm{O}}}+\theta_{18_{\mathrm{O}}}+\theta_{\mathrm{v}}=1$, where $\theta_{16_{\mathrm{O}}}$ $\left(\theta_{18_{\mathrm{O}}}\right)$ is the fraction of sites occupied by ${ }^{16} \mathrm{O}$ (or $\left.{ }^{18} \mathrm{O}\right)$, and $\theta_{\mathrm{v}}$ is the fraction of vacant sites $\left(\mathrm{V}_{\mathrm{O}, \mathrm{s}}^{\bullet \bullet}\right)$, and $h$ is the fraction of electron holes $\left(h^{\circ}\right)$.

The concentrations of surface species $\left(\mathrm{V}_{\mathrm{O}, \mathrm{s}}^{\bullet \bullet}, \mathrm{O}_{\mathrm{O}, \mathrm{s}}^{\times},{ }^{16} \mathrm{O}_{\mathrm{O}, \mathrm{s}}^{\times}\right)$ are calculated by assuming a Langmuir adsorption isotherm. This implies that only one site exists (all sites are energetically equivalent and there is no interaction between the adsorbed species), with this site being either occupied or vacant, and that the oxygen surface species are in equilibrium with the gas phase. The equilibrium constant $K$, which can be expressed as a Van't Hoff expression, is equal to the ratio $k_{\mathrm{f}} / k_{\mathrm{r}}$ :

$$
K=K^{\circ} \exp \left(\frac{-\Delta H}{R T}\right)
$$

with $\Delta H=E_{\mathrm{f}}-E_{\mathrm{r}}$

$$
K=\frac{\left(1-\theta_{\mathrm{v}}\right)^{2}}{\theta_{\mathrm{v}}^{2} P_{\mathrm{O}_{2}}}
$$

The oxygen non-stoichiometry $(\delta)$ is related to the fraction of vacancies through $\theta_{\mathrm{v}}=\delta / 3$ according to the general perovskite formula, $\mathrm{ABO}_{3-\delta}$.

Global mass balance:. The oxygen transport model is based on the one-dimensional pseudo-homogeneous diffusion convection 
equation for a fixed-bed reactor, implying the usual assumptions ${ }^{28}$ coupled with the oxygen exchange kinetics at the surface and oxygen diffusion through the bulk, described by eqn (16). Polarisation resistance is not taken into account in our model.

$$
\varepsilon_{\mathrm{b}} \frac{\partial P_{i}}{\partial t}=-u \frac{\partial P_{i}}{\partial z}-\left(1-\varepsilon_{\mathrm{b}}\right) L_{\mathrm{t}} \sum_{j=1}^{n} \nu_{i j} r_{j}
$$

where $P_{i}(\mathrm{~Pa})$ is the partial pressure of oxygen in the gas phase $\left(i={ }^{18} \mathrm{O}_{2},{ }^{16} \mathrm{O}_{2},{ }^{16} \mathrm{O}^{18} \mathrm{O}\right), t(\mathrm{~s})$ is time, $u_{\mathrm{s}}\left(\mathrm{m}_{\mathrm{G}}{ }^{3} \mathrm{~m}_{\mathrm{R}}{ }^{-2} \mathrm{~s}^{-1}\right)$ is the superficial gas velocity, $L_{\mathrm{t}}$ is the number of active sites $\left(\mathrm{mol} \mathrm{m}_{\mathrm{S}}{ }^{-3}\right)$, $\varepsilon_{\mathrm{b}}\left(\mathrm{m}_{\mathrm{G}}{ }^{3} \mathrm{~m}_{\mathrm{R}}{ }^{-3}\right)$ is the inter-granular void space, $D_{\mathrm{e}}\left(\mathrm{m}_{\mathrm{G}}{ }^{3} \mathrm{~m}_{\mathrm{R}}{ }^{-1} \mathrm{~s}^{-1}\right)$ is the effective axial diffusivity, $z\left(\mathrm{~m}_{\mathrm{R}}\right)$ is the axial reactor coordinate, $R\left(\mathrm{~J} \mathrm{~mol}^{-1} \mathrm{~K}^{-1}\right)$ is the gas constant, $T(\mathrm{~K})$ is the absolute temperature, $v_{i j}(-)$ is the stoichiometric coefficient for species $i$ in reaction $j$, and $r_{j}\left(\mathrm{~s}^{-1}\right)$ is the reaction rate of step $j$ (eqn (11) to (13)). Note that all four terms in eqn (16) are expressed in $\mathrm{Pa} \mathrm{S}^{-1}$.

The following boundary conditions were used:

$$
\begin{gathered}
z=0, P_{i}=P_{i}^{0} \\
z=L,\left.\frac{\partial P_{i}}{\partial z}\right|_{z=L}=0
\end{gathered}
$$

The Fick's law describes a variation of the concentration of oxygen through the bulk. Assuming spherical perovskite particles with radius $R_{\mathrm{p}}(\mathrm{m})$, Fick's second law then reads:

$$
\frac{\partial \theta_{z, r}}{\partial t}=D^{*}\left(\frac{\partial^{2} \theta_{i}}{\partial r^{2}}+\frac{2}{r} \frac{\partial \theta_{z, r}}{\partial r}\right)
$$

where $D^{*}\left(\mathrm{~m}_{\mathrm{S}}{ }^{2} \mathrm{~s}^{-1}\right)$ is the oxygen tracer diffusion coefficient, $\theta_{18_{\mathrm{O}}, r}$ $(-)$ is the ${ }^{18} \mathrm{O}$ fraction in the perovskite (equal to $C_{18_{\mathrm{O}}} /\left(C_{18_{\mathrm{O}}}+C_{16_{\mathrm{O}}}\right.$ $\left.+C_{\mathrm{V}}\right), C_{\mathrm{V}}\left(\mathrm{mol} \mathrm{m}_{\mathrm{S}}{ }^{-3}\right)$ being the oxygen vacancy concentration), and $r\left(\mathrm{~m}_{\mathrm{S}}\right)$ is the radial coordinate of the perovskite sphere.

Boundary conditions:

$$
\begin{aligned}
\text { At } r & =R_{\mathrm{p}} \\
-D^{*} \frac{3}{R_{\mathrm{p}}} \frac{\mathrm{d} \theta_{z}}{\mathrm{~d} r} & =\sum_{j=1}^{n} \nu_{i j} r_{j} \\
\text { At } r & =0 \\
\left.\frac{\partial \theta_{18 \mathrm{O}}}{\partial r}\right|_{r=0} & =0
\end{aligned}
$$

For the initial conditions, at $t<0$, the entire solid and the gas-phase oxygen are assumed to be composed of only ${ }^{16} \mathrm{O}$ isotope, as the perovskite has been pre-treated at the same temperature under a ${ }^{16} \mathrm{O}_{2}$ flow. $\left(P_{i}=P_{{ }^{16} \mathrm{O}_{2}}\right.$ and $\left.\theta_{\mathrm{O}}(r)=0\right)$. Then, at $t=0$, the partial pressure of ${ }^{18} \mathrm{O}_{2}$ is defined by eqn (20) with cst $\left(\mathrm{s}^{-1}\right)$ as a constant that depends on the fourway switching valve.

$$
P_{{ }^{18} \mathrm{O}_{2}}=P_{{ }^{18} \mathrm{O}_{2}}^{0} \frac{1-\exp (-\operatorname{cst} \times t)}{1+\exp (-\operatorname{cst} \times t)}
$$

The first-order differential equations were numerically integrated using the ODEPACK library. ${ }^{29}$ The non-linear least square regression analysis to estimate $k_{\mathrm{r}}, k_{\mathrm{f}}$ and $D^{*}$ was performed using a Levenberg-Marquardt minimization algorithm. ${ }^{30,31}$ After regression analysis, a statistical test was performed. ${ }^{32}$

\section{Results and discussion}

\section{Determination of equilibrium constant $(K)$ and vacancy fraction $\left(\theta_{v}\right)$ by TGA}

The evolution of the oxygen non-stoichiometry $(\delta)$ and thus the oxygen vacancies $\left(\theta_{\mathrm{v}}\right)$ of $\mathrm{La}_{0.6} \mathrm{Sr}_{0.4} \mathrm{Co}_{0.2} \mathrm{Fe}_{0.8} \mathrm{O}_{3-\delta}$ and $\mathrm{Ba}_{0.5} \mathrm{Sr}_{0.5} \mathrm{Co}_{0.8} \mathrm{Fe}_{0.2} \mathrm{O}_{3-\delta}$ with the temperature at fixed oxygen partial pressure can be followed by thermogravimetric analysis (TGA). Prior to TGA, the initial oxygen non-stoichiometry $(\delta)$ of $\mathrm{La}_{0.6} \mathrm{Sr}_{0.4} \mathrm{Co}_{0.2} \mathrm{Fe}_{0.8} \mathrm{O}_{3-\delta}$ and $\mathrm{Ba}_{0.5} \mathrm{Sr}_{0.5} \mathrm{Co}_{0.8} \mathrm{Fe}_{0.2} \mathrm{O}_{3-\delta}$ at room temperature was determined by iodometric titration. ${ }^{23,33} \mathrm{~A}$ series of 10 repetitive measurements on $\mathrm{La}_{0.6} \mathrm{Sr}_{0.4} \mathrm{Co}_{0.2} \mathrm{Fe}_{0.8} \mathrm{O}_{3-\delta}$ (resp. $\mathrm{Ba}_{0.5} \mathrm{Sr}_{0.5} \mathrm{Co}_{0.8} \mathrm{Fe}_{0.2} \mathrm{O}_{3-\delta}$ ) gave a non-stoichiometry $(\delta$ ) value equal to $0.03 \pm 0.01$ (resp. $0.41 \pm 0.01$ ) corresponding to a fraction of oxygen vacancies $\left(\theta_{v}\right)$ of 0.01 (resp. 0.137). Fig. 1 shows the evolution of the fraction of vacancies as a function of temperature as calculated from the weight loss of the TGA curve $($ ESI- $5 \dagger)\left(\theta_{\mathrm{v}}=\delta / 3\right)$ under two different fixed oxygen partial pressures for LSCF (Fig. 1a) and BSCF (Fig. 1b). The partial pressures of $21 \mathrm{kPa}$ of $\mathrm{O}_{2}$ (solid line) and $1 \mathrm{kPa}$ of $\mathrm{O}_{2}$ (dashed line) correspond to the conditions typically applied for air
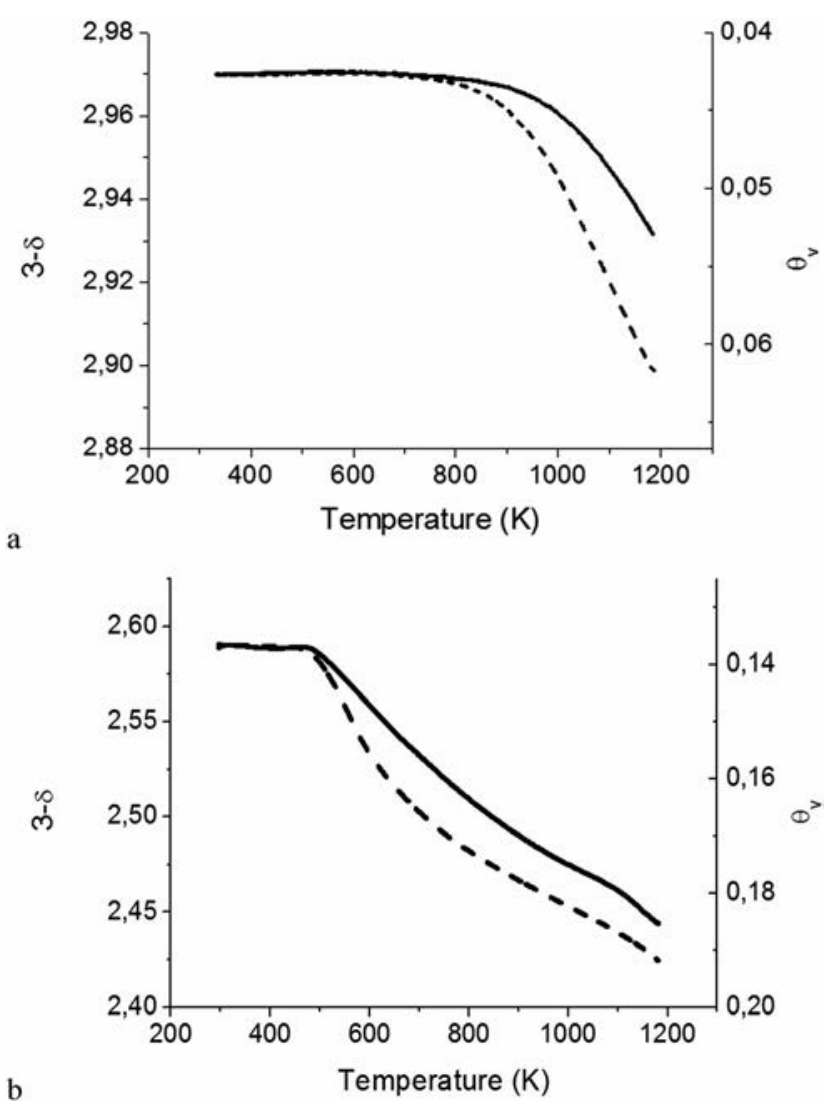

Fig. 1 TGA of LSCF (a) and BSCF (b) powders under $\mathrm{O}_{2} / \mathrm{N}_{2}$ flow, with $P_{\mathrm{O}_{2}}=21 \mathrm{kPa}$ (solid line) and $P_{\mathrm{O}_{2}}=1 \mathrm{kPa}$ (dashed line). 
separation in a membrane process, for the oxygen-rich side (air feed) and for the oxygen-lean side (permeate side), respectively. For LSCF, the TGA profiles are characterized by a long plateau corresponding to a constant fraction of vacancies up to relatively high temperature. The vacancy fractions increase with a linear rate starting from $823 \mathrm{~K}$ under $P_{\mathrm{O}_{2}}=1 \mathrm{kPa}$ and from $1050 \mathrm{~K}$ under $P_{\mathrm{O}_{2}}=21 \mathrm{kPa}$. Hence, we can observe an almost constant difference of oxygen vacancy concentration between the oxygen rich and lean conditions over the temperature range of interest. In contrast for BSCF, the fraction of vacancies $\left(\theta_{\mathrm{v}}\right)$ is stable only until $473 \mathrm{~K}$, then increases linearly with temperature in the case of $P_{\mathrm{O}_{2}}=21 \mathrm{kPa} \cdot{ }^{15,34,35}$ For lower oxygen pressure $\left(P_{\mathrm{O}_{2}}=1 \mathrm{kPa}\right)$, we can observe a pronounced oxygen loss at 550$650 \mathrm{~K}$ that accounts for a more thorough reduction of the solid, followed by a linear trend parallel to the former.

Our data fall within the typical range of oxygen nonstoichiometry generally found for $\mathrm{LSCF}^{36,37}$ and are in very good agreement with the data of Kriegel et al. ${ }^{34}$ for BSCF. ${ }^{38}$ In order to validate dynamic TGA measurement, additional TGA measurements were carried out by maintaining the sample at a constant temperature for a longer time before ramping to the next temperature level. A dwell-type temperature program gave non-stoichiometry values $(\delta)$ that were similar to those obtained by a continuous temperature ramp (ESI- $6 \dagger$ ). We can therefore conclude that oxygen adsorption/desorption and transport is more rapid and in quasi-equilibrium compared to the change in temperature.

No consensus exists in the literature regarding the stability of the BSCF material during TGA measurements. Stable behavior ${ }^{35}$ and slow partial decomposition ${ }^{38-40}$ have been reported in separate studies. We observed that after TGA measurements, the cell parameters remained constant within measurement errors (ESI-7 $\dagger$ ). In addition, we did not observe the formation of a new phase. Hence, the modification of the $\mathrm{Ba}_{0.5} \mathrm{Sr}_{0.5} \mathrm{Co}_{0.8} \mathrm{Fe}_{0.2} \mathrm{O}_{3-\delta}$ material during TGA experiments, if it does occur, is at least reversible. Similar conclusions for LSCF can be drawn up.

The adsorption equilibrium constant $(K)$ parameters were calculated for each oxygen pressure using eqn (15). This is the simplest approach for describing oxygen non-stoichiometry in perovskites. ${ }^{41}$ A Van't Hoff-type equation was used to describe the temperature dependence (eqn (14)) (ESI-8 $\dagger$ ). The corresponding parameters are presented in Table 1.

In the case of LSCF, the heat of adsorption does not significantly change under different oxygen partial pressures, meaning that the equilibrium constant varies similarly under a rich and lean-oxygen atmosphere. In contrast, significantly different parameters are found for BSCF, which should reveal

Table 1 Parameter estimates of the adsorption equilibrium constant $(K)$ using eqn (15) for two oxygen partial pressures (ESI-8)

\begin{tabular}{lrll}
\hline Perovskite & $P_{\mathrm{O}_{2}}(\mathrm{kPa})$ & $K^{\circ}\left(1 \mathrm{~Pa}^{-1}\right)$ & $\Delta H\left(\mathrm{~kJ} \mathrm{~mol}^{-1}\right)$ \\
\hline LSCF & 1 & $(5.0 \pm 0.07) \times 10^{-2}$ & $-41.6 \pm 0.9$ \\
LSCF & 21 & $(7.2 \pm 0.07) \times 10^{-3}$ & $-36.3 \pm 0.9$ \\
BSCF & 1 & $(2.4 \pm 0.05) \times 10^{-4}$ & $-42.5 \pm 0.9$ \\
BSCF & 21 & $(2.7 \pm 0.05) \times 10^{-3}$ & $-12.1 \pm 0.1$
\end{tabular}

a structural change at the solid surface leading to different adsorption-desorption properties. The physical interpretation of these data is rather problematic. Thermodynamic models that describe the defect chemistry have been developed, ${ }^{42}$ but no specific model for BSCF has yet been reported. The oxygen non-stoichiometry behaviour of BSCF is complex due to the presence of both cobalt and iron cations in three different valence states. ${ }^{43}$ The higher enthalpy at lower partial pressure of oxygen is consistent with an enthalpy that decreases with increasing oxygen vacancy concentration (or $\delta$ ), as observed by Mizusaki et al. for $\mathrm{La}_{0.9} \mathrm{Sr}_{0.1} \mathrm{CrO}_{3-\delta .}{ }^{42}$

The semi-empirical model proposed by Yang and Lin (eqn (21)) did not work either for BSCF, because $n$ varied at each temperature. ${ }^{44}$

$$
\left.\delta=\frac{3 K P_{\mathrm{O}_{2}}^{n}}{1+K P_{\mathrm{O}_{2}}^{n}}\right)
$$

As we are proposing a straightforward, versatile method for the screening of perovskite powders to extract transport parameters in order to predict the oxygen semi-permeability, we have continued to use the simplified model as given by eqn (15) with two sets of values: one on the air side and one on the permeate side. The development of a theoretically-based model for the full description of the defect chemistry as a function of oxygen partial pressures and temperatures is outside the scope of this study.

\section{Modelling of oxygen isotopic exchange and estimation of surface exchange kinetic coefficients $\left(k_{\mathrm{r}}, k_{\mathrm{f}}\right)$}

The TGA data could not be described over the entire range of oxygen pressures using a simple, one-parameter defect model. In order to avoid the need to develop a full defect model, isotopic oxygen exchange measurements were carried out under the same conditions applied for TGA measurements, namely $1 \mathrm{kPa}$ and $21 \mathrm{kPa}$. By fixing the equilibrium oxygen adsorption constant at the values obtained from TGA experiments, the forward adsorption rate constant can be estimated from the isotopic oxygen exchange experiments.

Fig. 2 and 3 show examples of oxygen exchange experiments for two partial pressures of oxygen at three temperatures for LSCF and BSCF, respectively. The exchange took about an order of magnitude longer at $P_{\mathrm{O}_{2}}=1 \mathrm{kPa}$ than at $P_{\mathrm{O}_{2}}=21 \mathrm{kPa}$. On the other hand, the temperature initially had an effect at low temperatures, but the effect levelled out quickly above $900 \mathrm{~K}$. The integration of the $0.5 \times P^{32} \mathrm{O}_{2}+P^{16} \mathrm{O}^{18} \mathrm{O}$ signals gave the amount of exchanged oxygen. For experiments carried out at $P_{\mathrm{O}_{2}}=21 \mathrm{kPa}$ and $T=973 \mathrm{~K}, 86 \%$ and $95 \%$ of all oxygen atoms are exchanged for LSCF and BSCF, respectively. In contrast, only $50 \%$ of oxygen atoms are exchanged for both at $P_{\mathrm{O}_{2}}=1 \mathrm{kPa}$ in 35 minutes. For cost reasons, the exchange curves were not recorded until the end of the exchange. It is known that structure changes of BSCF occur in the range of conditions applied here. ${ }^{5}$ Nevertheless, we did not observe significant modifications of the exchange profiles after $1 \mathrm{~h}$ of exposure under given temperature and oxygen partial pressure conditions. 

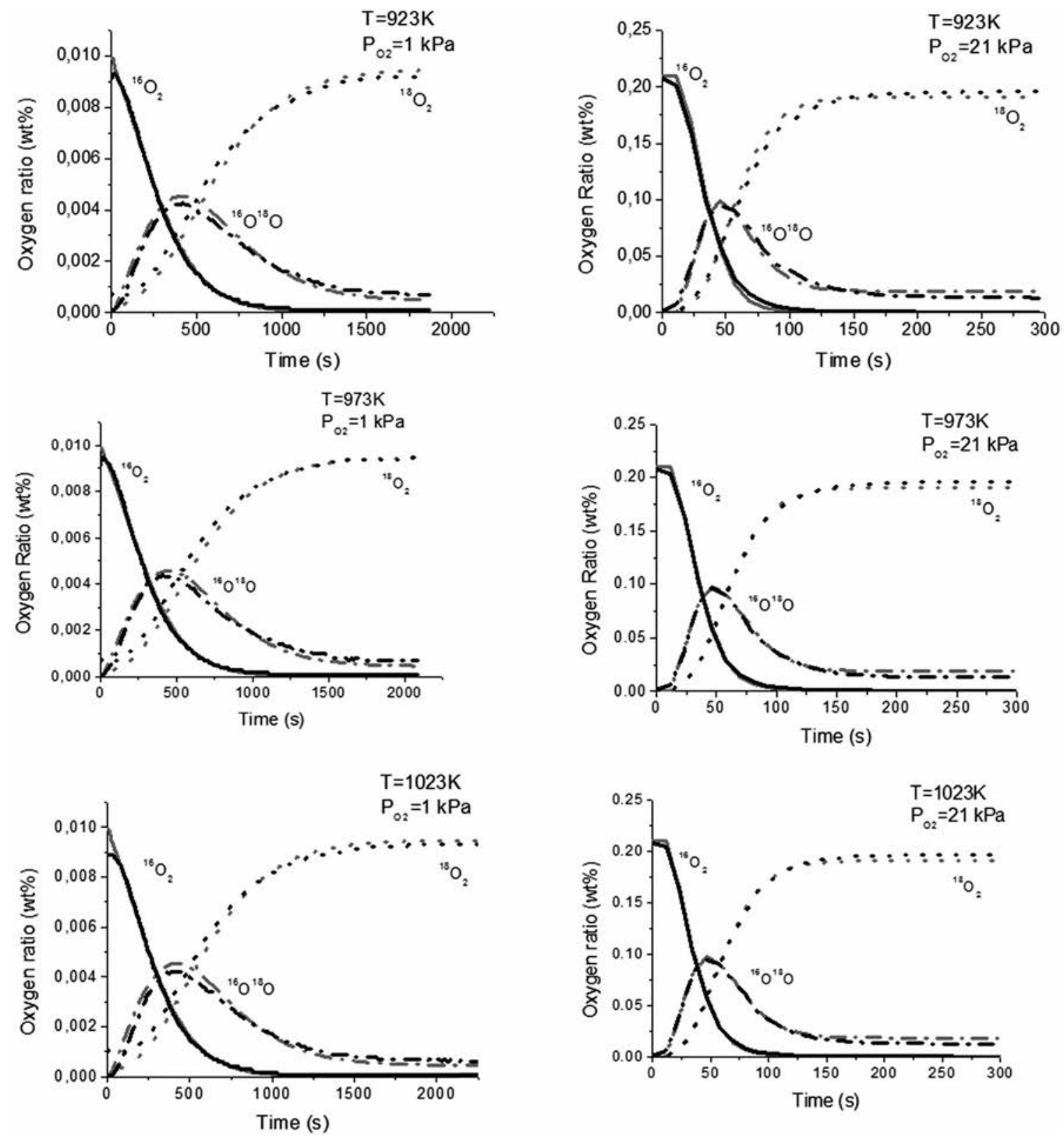

Fig. 2 SSITKA experiments (black) and model curves (light grey), ${ }^{16} \mathrm{O}_{2}(\mathrm{~g})$ (solid line), ${ }^{16} \mathrm{O}{ }^{18} \mathrm{O}(\mathrm{g})$ (dashed line), ${ }^{18} \mathrm{O}_{2}(\mathrm{~g})$ (dotted line) at different partial pressures of oxygen and different temperatures for LSCF.

The oxygen exchange curves $\left(P^{16} \mathrm{O}_{2}\right.$ and $\left.P^{16} \mathrm{O}^{18} \mathrm{O}\right)$ were modelled for each level of oxygen partial pressure separately, but including all temperatures simultaneously. Initial regression analysis showed that quasi-equilibrium of the exchange rates was established at the time scale of the experiment. Thus only the forward rate parameters $\left(k_{\mathrm{f}}\right)$ were estimated during the regression analysis, and the reverse rate parameters $\left(k_{\mathrm{r}}\right)$ were calculated from the equilibrium rate constants $\left(K=k_{\mathrm{f}} / k_{\mathrm{r}}\right)$ determined from the TGA experiments (Table 1). Using the electroneutrality condition, the electron hole concentration $[h]$ was estimated to be on the order of $2 \times \theta_{\mathrm{v}}$. The value of the rate constant was adjusted accordingly. In the temperature interval between 650 and $900{ }^{\circ} \mathrm{C}$ the concentration $[h]$ varies roughly
$30 \%$, which is negligible compared to the change in the oxygen exchange rate. Thus an intrinsic activation energy can be obtained from the exchange experiments. In addition to the oxygen exchange parameters, the characteristic time constant $\left(D / r^{2}\right)$ for oxygen transport was estimated from the isotopic exchange response curves. In Fig. 2, the model-predicted response curves are compared to the experimental curves for LSCF. A good fit is obtained under all temperatures and pressure conditions. The surface parameter and diffusion estimates are reported in Tables 2 and 4, respectively. Similarly, Fig. 3 compares the model-predicted response curves with the experimental curves for BSCF. A good fit was obtained at both oxygen partial pressures and at all temperatures. The surface 

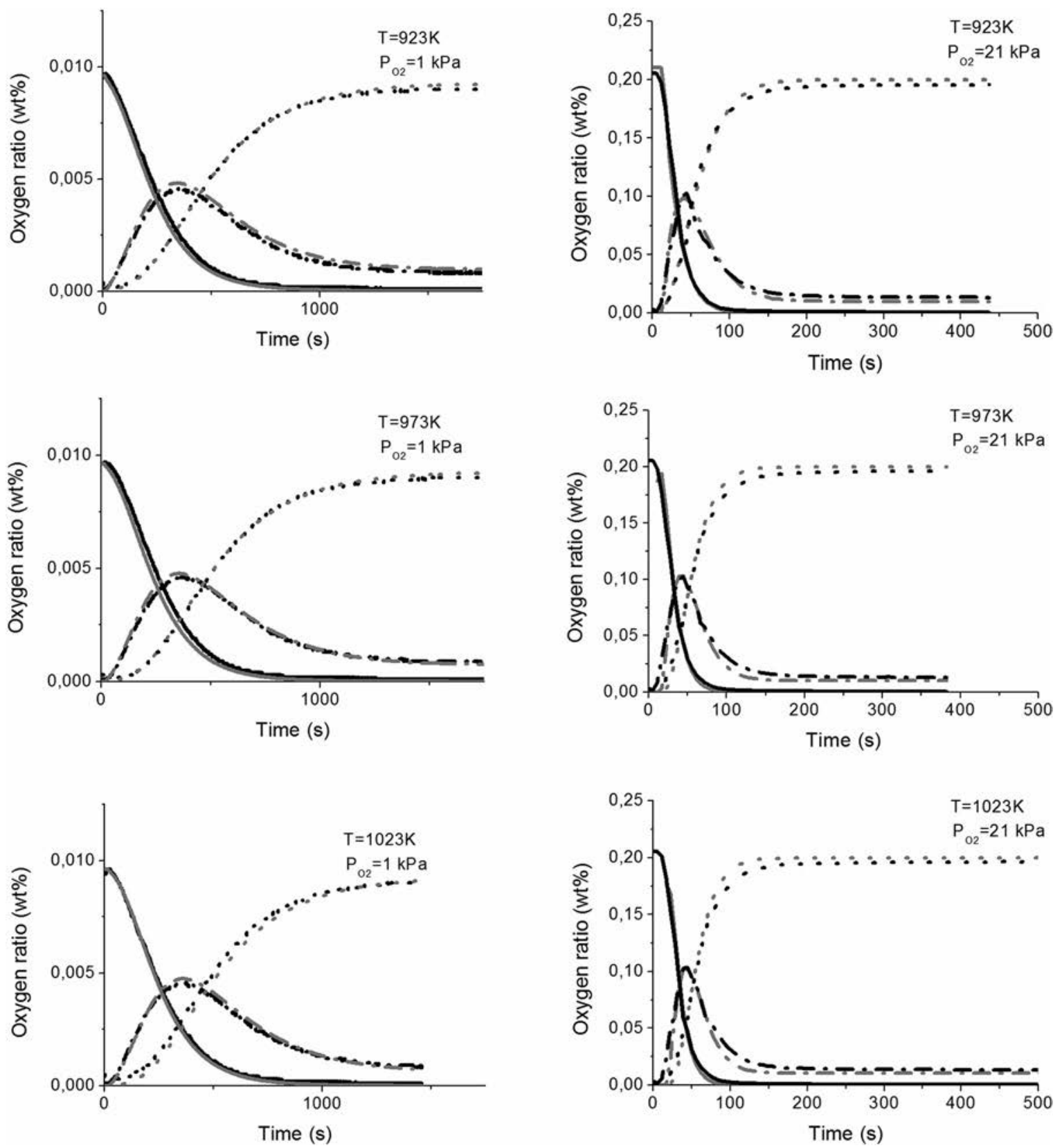

Fig. 3 SSITKA experiments (black) and model curves (light grey), ${ }^{16} \mathrm{O}_{2}(\mathrm{~g})$ (solid line), ${ }^{16} \mathrm{O}{ }^{18} \mathrm{O}(\mathrm{g})$ (dashed line), ${ }^{18} \mathrm{O}_{2}(\mathrm{~g})$ (dotted line) at different partial pressures of oxygen and different temperatures for BSCF.

parameter and diffusion estimates are reported in Tables 3 and 4, respectively.

We can see that pre-exponential factors $\left(k_{\mathrm{r}}^{\circ}, k_{\mathrm{f}}^{\circ}\right)$ and activation energies $\left(E_{\mathrm{r}}, E_{\mathrm{f}}\right)$ for the reverse and forward reactions estimated from the SSITKA/TGA approach match very well with the results of $\mathrm{Xu}$ and Thomson obtained by modelling the semipermeability data on the LSCF membrane. ${ }^{12}$ Thus, we can conclude on the validity of this novel microkinetic approach which uses a powder instead of a membrane for the estimation of reverse and forward kinetic parameters.

We can note that kinetics parameters for LSCF do not change significantly when measured at $P_{\mathrm{O}_{2}}=1 \mathrm{kPa}$ and $P_{\mathrm{O}_{2}}=21 \mathrm{kPa}$.
Other experimental approaches (isotope exchange depth profiling (IEDP) and electrical conductivity relaxation (ECR)) lead to global kinetic rate parameters that do not take the oxygen vacancies into account and thus kinetic parameters cannot be directly compared. We can note, however, that Sahibzada et al. ${ }^{20}$ found variations of global kinetic parameter and chemical diffusion coefficient as a function of the partial pressure of oxygen for $\mathrm{La}_{0.6} \mathrm{Sr}_{0.4} \mathrm{Co}_{0.2} \mathrm{Fe}_{0.8} \mathrm{O}_{3-\delta}$ (ref. 20) for very low partial pressure of oxygen (lower the $0.1 \mathrm{kPa}$ ).

In contrast, for BSCF we can observe significant larger activation energy of the reverse reaction at lean oxygen pressure, whereas for the forward reaction the activation energies are 
Table 2 Kinetic parameters estimated from regression analysis of the isotopic oxygen exchange response curves. The confidence intervals are estimated at $95 \%$. For comparison, the estimated parameters are reported in two different units. Results from $\mathrm{Xu}^{\mathrm{and}} \mathrm{Thomson}{ }^{12}$ obtained on $\mathrm{La}_{0.6} \mathrm{Sr}_{0.4} \mathrm{CO}_{0.2} \mathrm{Fe}_{0.8} \mathrm{O}_{3-\delta}$ membrane semi-permeability data model are reported

\begin{tabular}{|c|c|c|c|c|c|c|}
\hline \multirow{2}{*}{$\frac{\text { LSCF }}{\text { Shape }}$} & \multirow[b]{2}{*}{$P_{\mathrm{O}_{2}}(\mathrm{kPa})$} & \multicolumn{2}{|c|}{ Surface reverse kinetic parameter } & \multicolumn{2}{|c|}{ Surface forward kinetic parameter } & \multirow[b]{2}{*}{ Ref. } \\
\hline & & $k_{\mathrm{r}}^{\circ}\left(\mathrm{s}^{-1}\right)$ & $E_{\mathrm{r}}\left(\mathrm{kJ} \mathrm{mol}^{-1}\right)$ & $k_{\mathrm{f}}^{\circ}\left(\mathrm{Pa}^{-1} \mathrm{~s}^{-1}\right)$ & $E_{\mathrm{f}}\left(\mathrm{kJ} \mathrm{mol}^{-1}\right)$ & \\
\hline $\begin{array}{l}\text { Powder } \\
\text { Powder }\end{array}$ & $\begin{array}{l}21 \\
1\end{array}$ & $\begin{array}{l}(2.7 \pm 0.07) \times 10^{11} \\
(2.7 \pm 0.07) \times 10^{11}\end{array}$ & $\begin{array}{l}239 \pm 25 \\
243 \pm 25\end{array}$ & $\begin{array}{l}(8.1 \pm 0.1) \times 10^{7} \\
(4.4 \pm 0.05) \times 10^{7}\end{array}$ & $\begin{array}{l}198 \pm 16 \\
207 \pm 16\end{array}$ & $\begin{array}{l}\text { This work } \\
\text { This work }\end{array}$ \\
\hline$\underline{\text { LSCF }}$ & $P_{\mathrm{O}_{2}}(\mathrm{kPa})$ & \multicolumn{2}{|c|}{ Surface reverse kinetic parameter } & \multicolumn{2}{|c|}{ Surface forward kinetic parameter } & Ref. \\
\hline Shape & & $k_{\mathrm{r}}^{\circ}\left(\mathrm{mol} \mathrm{cm} \mathrm{c}^{-2} \mathrm{~s}^{-1}\right)$ & $E_{\mathrm{r}}\left(\mathrm{kJ} \mathrm{mol}^{-1}\right)$ & $k_{\mathrm{f}}^{\circ}\left(\mathrm{cm} \mathrm{atm}^{-0.5} \mathrm{~s}^{-1}\right)$ & $E_{\mathrm{f}}\left(\mathrm{kJ} \mathrm{mol}^{-1}\right)$ & \\
\hline $\begin{array}{l}\text { Powder } \\
\text { Powder } \\
\text { Membrane }\end{array}$ & $\begin{array}{l}21 \\
1 \\
\text { n.d. }\end{array}$ & $\begin{array}{l}(5.5 \pm 0.15) \times 10^{4} \\
(5.5 \pm 0.15) \times 10^{4} \\
2.07 \times 10^{4}\end{array}$ & $\begin{array}{l}239 \pm 25 \\
243 \pm 25 \\
241.3\end{array}$ & $\begin{array}{l}(5.9 \pm 0.1) \times 10^{6} \\
(3.2 \pm 0.03) \times 10^{6} \\
5.90 \times 10^{6}\end{array}$ & $\begin{array}{l}198 \pm 16 \\
207 \pm 16 \\
226.9\end{array}$ & $\begin{array}{l}\text { This work } \\
\text { This work } \\
12\end{array}$ \\
\hline
\end{tabular}

n.d. not determined.

Table 3 Kinetic parameters estimated from regression analysis of the isotopic oxygen exchange response curves for $\mathrm{Ba}_{0.5} \mathrm{Sr}_{0.5} \mathrm{Co}_{0.8} \mathrm{Fe}_{0.2} \mathrm{O}_{3-\delta}$. The confidence intervals are estimated at $95 \%$

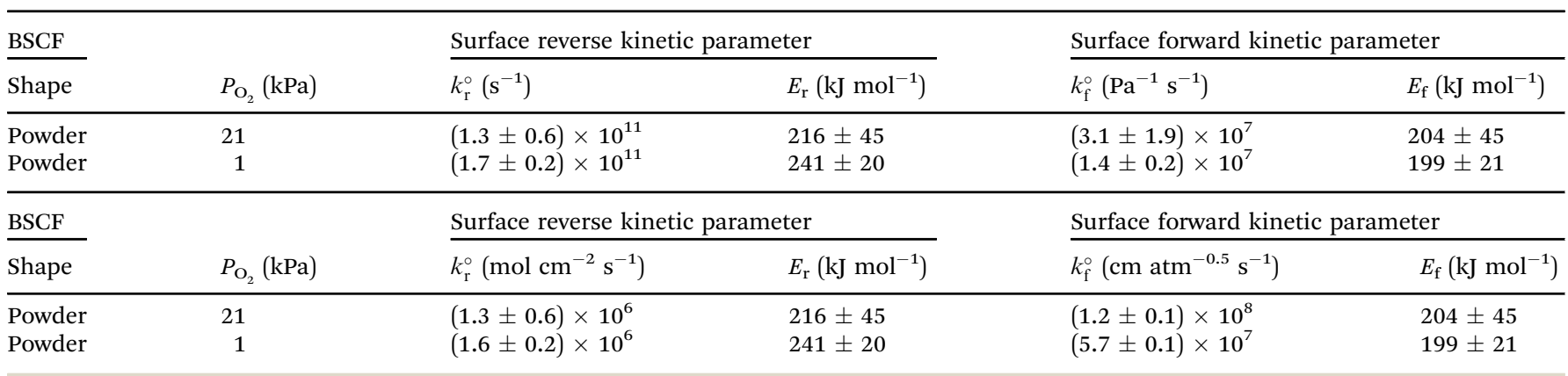

Table 4 Characteristic time constants for diffusion estimates from regression analysis of the oxygen exchange response curve between 700 and $900{ }^{\circ} \mathrm{C}$, and self-diffusion parameter calculated using the crystallite radius ( $r$ ) equal to 0.16 for LSCF and $3.5 \mu \mathrm{m}$ for BSCF. Confidence intervals estimated at $95 \%$

\begin{tabular}{lclcc}
\hline Material & $\begin{array}{c}P_{\mathrm{O}_{2}} \\
(\mathrm{kPa})\end{array}$ & $D^{* \circ} / r^{2}\left(\mathrm{~s}^{-1}\right)$ & $D^{* \circ}\left(\mathrm{cm}^{2} \mathrm{~s}^{-1}\right)$ & $E_{\mathrm{d}}\left(\mathrm{kJ} \mathrm{mol}^{-1}\right)$ \\
\hline LSCF & 21 & $(2.0 \pm 0.4) \times 10^{5}$ & $(5 \pm 1) \times 10^{-5}$ & $76.9 \pm 10$ \\
LSCF & 1 & $(3.0 \pm 0.6) \times 10^{5}$ & $(7.6 \pm 1.5) \times 10^{-5}$ & $76.9 \pm 10$ \\
BSCF & 21 & $(5.3 \pm 0.4) \times 10^{2}$ & $(6.5 \pm 0.4) \times 10^{-5}$ & $35 \pm 16$ \\
BSCF & 1 & $(7.4 \pm 0.9) \times 10^{3}$ & $(9.1 \pm 0.9) \times 10^{-4}$ & $48 \pm 16$ \\
\hline
\end{tabular}

very similar. This result is supported by DFT calculations which indicate that a simple "defect-chemical model" for BSCF is not applicable. ${ }^{45}$ As a consequence, for BSCF the rates of desorption of oxygen are lower than for adsorption at low oxygen partial pressure which would represent the sweep side in a membrane operation. These experimental results are opposite to $\mathrm{Xu}$ and Thomson hypothesis. ${ }^{12}$ Unfortunately, to the best of our knowledge no data related to intrinsic kinetic parameters have been reported in the literature for BSCF materials, but only surface exchange coefficients ${ }^{46,47}$ which does not allow direct comparison with our data. Moreover, the values of the surface exchange coefficients in the two studies vary by two orders of magnitude. ${ }^{46,47}$

\section{Estimation of diffusion coefficients from characteristic time}

Oxygen exchange experiments give access to the characteristic diffusion time, which is the ratio of the diffusion coefficient to the square of the characteristic length $\left(D^{*} / r^{2}\right)$. This is similar to all other techniques used for the measurement of diffusion coefficients. If the diffusion measurements are carried out directly on the shaped material for the intended application, then the value of $D^{*} / r^{2}$ can be used directly. In our context, the method we have developed aims to predict the permeation of membranes from kinetic modelling carried out on the corresponding powders. In this case, the characteristic length of diffusion is not the same. For the membrane application the length corresponds to the thickness of the membrane, whereas for powder it corresponds to the crystallite size. Therefore, the crystallite size for the powders used in this study needs to be determined. The crystallite diameter can be estimated directly from SEM image analysis (Fig. 4). The size distribution of the crystallites was measured by counting 250 crystallites (Fig. 4). The distribution is centred at $7 \mu \mathrm{m}$ using a non-linear Gauss curve fit (Fig. 5). Independently, the mean diameter of the crystallite with an accessible surface was determined by $\mathrm{N}_{2}$ adsorption measurements at $77 \mathrm{~K}$. For LSCF, the BET surface area is equal to $3.2 \mathrm{~m}^{2} \mathrm{~g}^{-1}$ and $\rho=5.89 \mathrm{~g} \mathrm{~cm}^{-3}$ which leads to a crystallite diameter $\left(d_{\text {crys }}\right)$ of $0.32 \mu \mathrm{m}$. Thus, we set the crystallite radius $(r)$ to $0.16 \mu \mathrm{m}$ for the estimation of the diffusion parameter (Table 4).

For BSCF, the BET surface area is equal to $150 \pm 1 \mathrm{~m}^{2} \mathrm{~kg}^{-1}$, which leads to a crystallite diameter $\left(d_{\text {crys }}\right)$ of $7.2 \mu \mathrm{m}$, in good agreement with SEM image analysis (Fig. 4). The crystallite radius $(r)$ has been set to $3.5 \mu \mathrm{m}$ for allowing the estimation of the diffusion parameter (Table 4 ). 

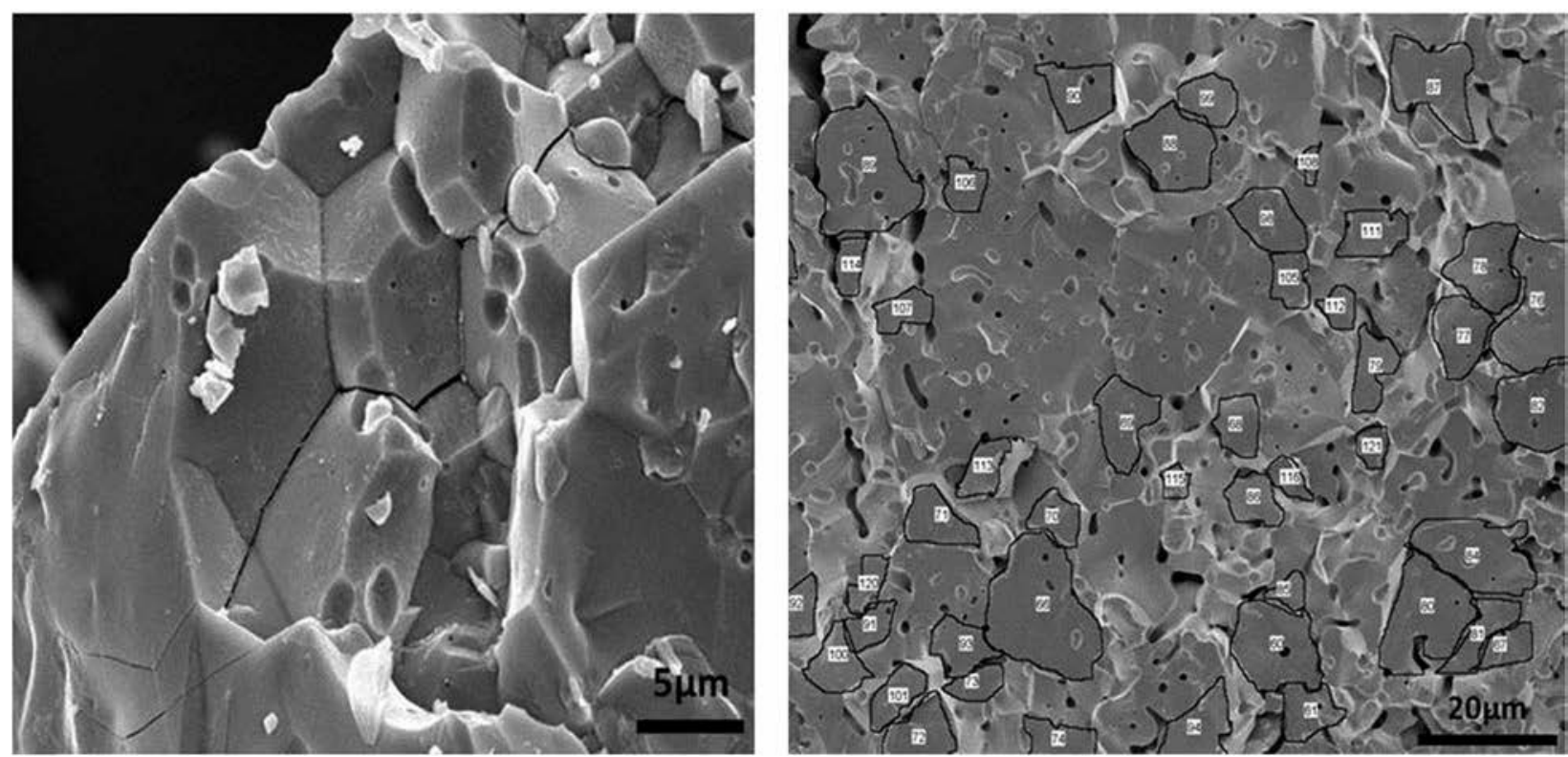

Fig. 4 SEM images of a BSCF grain: surface of a grain $(\times 4000)$ (left), bulk $(\times 1000)$ (right). Crystallite size distribution measurement using the ImageJ software.

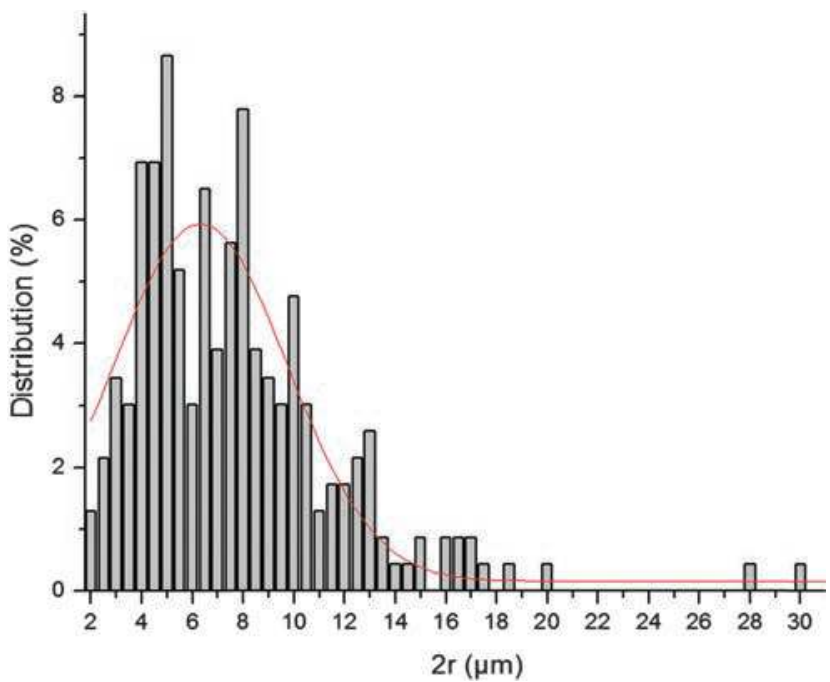

Fig. 5 Distribution of the crystallite size from SEM image analysis for the BSCF material.

Isotopic exchange measurements were carried out on sieved powder with a mean grain size of about $500 \mu \mathrm{m}$. Assuming a mean crystallite radius $(r)$ of $0.16 \mu \mathrm{m}$ for LSCF and $3.5 \mu \mathrm{m}$ for BSCF, a grain consists an average of 10000000 crystallites for LSCF and 5000 for BSCF, respectively. The transport measurement in a grain is thus representative of the transport phenomena occurring in a continuous body such as a film or a membrane. We can also conclude that SSITKA measurements that are carried out over powders can account well for transport phenomena at the grain boundaries. In other words, the gentle crushing of the membrane into grains of $500 \mu \mathrm{m}$ does not alter the microstructure of the solid.

From SSITKA modelling, the self-diffusion parameters $\left(D^{*}\right)$ were calculated at two different oxygen partial pressures using the estimated characteristic diffusion times and the mean crystallite radius associated to each solids (Table 4). We can see major differences in the diffusion energies between LSCF and BSCF. As for the surface kinetic parameters of LSCF, the diffusion energy $\left(E_{\mathrm{d}}=76.9 \pm 10\right)$ does not vary with the partial pressure. In contrast, the diffusion energy of BSCF significantly varies with the oxygen pressure, in line with results found elsewhere for $\mathrm{La}_{0.9} \mathrm{Sr}_{0.1} \mathrm{CrO}_{3-\delta} \cdot{ }^{42}$ In addition, the activation energies of BSCF are much smaller (35-48 $\mathrm{kJ} \mathrm{mol}^{-1}$ ) when compared to LSCF which is in very good agreement with DFT calculations found elsewhere $\left(43 \mathrm{~kJ} \mathrm{~mol}^{-1}\right) .{ }^{45}$

The comparison of diffusion results with literature data is not straightforward since they can be obtained either under equilibrated or non-equilibrated conditions. In addition, there are different types of diffusion parameters. The vacancy diffusivity, $D_{\mathrm{v}}$, describes the rate of oxygen vacancy transport. The vacancy diffusion constant $\left(D_{\mathrm{v}}\right)$ is usually obtained from regression analysis using membrane permeation data. The self-diffusion of oxygen $\left(D^{*}\right)$ and oxygen vacancy diffusion $\left(D_{\mathrm{v}}\right)$ coefficients are linked through the oxygen vacancy molar fraction $\theta_{\mathrm{v}}$ by the following expression (22). The vacancy diffusion constant $\left(D_{\mathrm{v}}\right)$ of LSCF are calculated using eqn (22) and compared with results of $\mathrm{Xu}$ and Thomson in Table 5. Here again, we observe a perfect match between results obtained with the novel microkinetic approach from powder

Table 5 Comparison of calculated oxygen self-diffusion rates under the given conditions with literature results for $\mathrm{La}_{0.6} \mathrm{Sr}_{0.4} \mathrm{Co}_{0.2} \mathrm{Fe}_{0.8} \mathrm{O}_{3-\delta}$

\begin{tabular}{lclll} 
Shape & $P_{\mathrm{O}_{2}}(\mathrm{kPa})$ & $D_{\mathrm{v}}^{\circ}\left(10^{2} \mathrm{~cm}^{2} \mathrm{~s}^{-1}\right)$ & $E\left(\mathrm{~kJ} \mathrm{~mol}^{-1}\right)$ & Ref. \\
\hline Powder & 21 & $0.73 \pm 0.1$ & $76.9 \pm 10$ & This work \\
Powder & 1 & $1.10 \pm 0.2$ & $76.9 \pm 10$ & This work \\
Membrane & & 1.58 & 73.9 & 12
\end{tabular}


Table 6 Comparison of calculated oxygen self-diffusion rates under the given conditions with literature results for $\mathrm{Ba}_{0.5} \mathrm{Sr}_{0.5} \mathrm{Co}_{0.8} \mathrm{Fe}_{0.2} \mathrm{O}_{3-\delta}$

\begin{tabular}{|c|c|c|c|c|c|}
\hline Formulation & Method & $T(\mathrm{~K})$ & $P_{\mathrm{O}_{2}}^{\prime}(\mathrm{kPa})$ & $\begin{array}{l}D^{*} \\
\left(\mathrm{~cm}^{2} \mathrm{~s}^{-1}\right)\end{array}$ & Ref. \\
\hline Membrane & IEDP & 973 & 50 & $8.0 \times 10^{-7}$ & 50 \\
\hline Membrane & $\begin{array}{l}\text { Conductivity } \\
\text { relaxation }\end{array}$ & 973 & 2.1 & $1.09 \times 10^{-7}$ & 15 \\
\hline Membrane & $\begin{array}{l}\text { Conductivity } \\
\text { relaxation }\end{array}$ & & 1 & $3.99 \times 10^{-8}$ & 15 \\
\hline Powder & SSITKA & 973 & 21 & $8.3 \times 10^{-7}$ & Our work \\
\hline Powder & SSITKA & 973 & 1 & $2.4 \times 10^{-6}$ & Our work \\
\hline
\end{tabular}

and the modelling of semi-permeability data by $\mathrm{Xu}$ and Thomson. ${ }^{12}$

$$
D_{\mathrm{v}}=\frac{D^{*}\left(T, P_{\mathrm{O}_{2}}\right)\left(1-\theta_{\mathrm{v}}\left(T, P_{\mathrm{O}_{2}}\right)\right)}{f^{*} \theta_{\mathrm{v}}\left(T, P_{\mathrm{O}_{2}}\right)}
$$

Ishigaki et $a .^{48}$ calculated the correlation factor $\left(f^{*}\right)$ of 0.69 for perovskites.

The comparison of oxygen conductivity is another way to validate the diffusion data obtained by the microkinetic approach. The Nernst-Einstein equation allows the calculation of the oxygen conductivity $\left(\sigma_{0}\right)$ from the oxygen self-diffusion $\left(D^{*}\right)$ according to the formula:

$$
\sigma_{0}=\frac{4 F^{2}(3-\delta) D^{*}}{R T V_{\mathrm{m}}}
$$

$F$ is the Faraday constant, $R$ the gas constant and $V_{\mathrm{m}}$ the molar volume in $\mathrm{mol} \mathrm{cm} \mathrm{cm}^{-3}$ (ESI-10†).

For $\mathrm{La}_{0.6} \mathrm{Sr}_{0.4} \mathrm{Co}_{0.2} \mathrm{Fe}_{0.8} \mathrm{O}_{3-\delta}$ with $P_{\mathrm{O}_{2}}=21 \mathrm{kPa}$, Ullman et al. ${ }^{49}$ found an oxygen conductivity of $0.007 \mathrm{~S} \mathrm{~cm}^{-1}$. In this work, the oxygen conductivities calculated at $1073 \mathrm{~K}$, at $1 \mathrm{kPa}$ and $21 \mathrm{kPa}$ are 0.003 and $0.005 \mathrm{~S} \mathrm{~cm}^{-1}$, respectively, in very good agreement with the literature.

The self-diffusion rates calculated under given conditions of temperature and oxygen pressure are compared with the literature results available for $\mathrm{Ba}_{0.5} \mathrm{Sr}_{0.5} \mathrm{Co}_{0.8} \mathrm{Fe}_{0.2} \mathrm{O}_{3-\delta}$ (Table 6). Good agreement is found with the values of the tracer diffusion study, but not with those obtained by relaxation conductivity. The latter deviation is not of obvious origin, since it can arise either from a different material microstructure or from the fact that the measurement technique used is not a steady-state method.

\section{General discussion}

In this section, we describe the pros and cons of the different techniques and approaches for the estimation of kinetic and diffusion parameters in oxygen transport materials.

The model of $\mathrm{Xu}$ and Thomson was a major progress for the modelling of oxygen semi-permeability of perovskite membranes. Although a good fit with experimental data is obtained, the authors indicate that their model fails to describe the flux when the oxygen concentration is varied on the retentate side. Aside from modelling limitations, the estimation of transport coefficients from membrane testing presents practical challenges. The development of dense membranes is a very tedious process achieved mainly through trial and error. ${ }^{51}$ In addition, the high temperatures required for good permeability often cause membrane breakdown during testing and/or issues with sealing. Consequently, alternative measurement methods are highly desired.

Electrical conductivity relaxation (ECR) allows the measurement of the oxygen self-diffusion parameter, $D_{\text {chem, }}$ and the global exchange kinetic parameter, $k_{\text {chem. }} \cdot{ }^{14-16}$ The measurements are carried out on sintered samples, which are then cut to obtain thin films. The electrical signal is measured under transient conditions by applying a step change in the pressure of oxygen. Unfortunately, this modifies the concentration of oxygen vacancies during the measurements and therefore introduces a bias in the estimation of adsorption and diffusion rate constants. The estimation of kinetic constants in a nonequilibrated regime usually makes the modelling and the parameter estimation quite complex. Solid electrolyte coulometry $(\mathrm{SEC})^{20}$ is an attractive alternative relaxation technique which is easier to use since measurements are carried out on powders. However, the concerns related to non-steady-state measurements still remain. ${ }^{20}$

Oxygen isotopic exchange techniques for which oxygen concentration steps are carried out under equilibrium conditions by replacing ${ }^{16} \mathrm{O}_{2}$ by ${ }^{18} \mathrm{O}_{2}$ are a very appropriate alternative solution. The oxygen isotopic exchange takes place under steady-state conditions, thus the oxygen partial pressure and the concentration of oxygen vacancies are constant during the measurements. This also greatly simplifies the modelling and the parameter estimation. The technical and modelling advantages of steady-state transient methods have been described by Shannon and Goodwin. ${ }^{52}$

The group of Carter and Steele ${ }^{17}$ developed a steady-state isotopic ${ }^{18} \mathrm{O} /{ }^{16} \mathrm{O}$ technique called isotopic exchange depth profiling (IEDP), which allows the estimation of the global surface exchange $\left(k^{*}\right)$ and diffusion $\left(D^{*}\right)$ parameters. ${ }^{18,19}$ This technique is based on surface thin-film analysis by secondary ion mass spectrometry (SIMS), which provides a three-dimensional map of the ${ }^{18} \mathrm{O}$ distribution. ${ }^{53-55}$ The assumption for the ${ }^{18} \mathrm{O}$ transport modelling is that the rate of isotope exchange across the gas/solid interface is considered to be directly proportional to the difference in isotope concentration between the gas and the solid. Vacancy concentrations are not taken into account in the modelling. Diffusion is defined by Fick's law and is directly proportional to the exchange kinetics based on the film model.

$$
-\left.D^{*} \frac{\partial C}{\partial x}\right|_{x=0}=k^{*}\left(C_{\mathrm{s}}-C_{\mathrm{g}}\right)
$$

$D^{*}$ is the self-diffusion parameter, and $C_{\mathrm{g}}$ and $C_{\mathrm{s}}$ are, respectively, the concentration in isotopic oxygen in the gas phase and in the solid phase. The IEDP technique is advantageous because it is carried out on a thin film that allows the direct application of the estimated parameters to the transport modelling of a flat membrane, due to identical geometry. ${ }^{18}$ 
On the other hand, each experimental condition requires a new sample that must be prepared and shaped as a thin film. For this reason, sample preparation requirements make this technique tedious to use. In addition, this method usually requires a relatively high oxygen pressure $\left(P_{\mathrm{O}_{2}}=70 \mathrm{kPa}\right)$ to obtain sufficient analytical resolution. This high oxygen partial pressure is not, however, consistent with membrane processes, which operate at much lower oxygen partial pressures, typically in the range of 1-21 $\mathrm{kPa}$.

Isotopic ${ }^{18} \mathrm{O}_{2} /{ }^{16} \mathrm{O}_{2}$ exchange has also been carried out on samples in powder form for the estimation of the rate of adsorption and desorption, the concentration of oxygen on catalysts, and the surface diffusion coefficient of oxygen. ${ }^{56}$ In contrast to the IEDP technique, in which the ${ }^{16} \mathrm{O} /{ }^{18} \mathrm{O}$ gradient is measured in the solid after a given time, steady-state isotopic transient kinetic analysis (SSITKA) is a time-resolved method that analyzes the evolution of the isotope concentration in the gas phase by online mass spectrometry. The use of powders accelerates the experimental part of the work, while the use of intrinsic kinetic and transport parameters allows a coherent description of oxygen permeation through the membrane. The latter has been accomplished in this study by describing all the processes on the microkinetic scale (at the level of the elementary steps) and not, like most approaches reported in the literature so far, by lumped apparent parameters (a macrokinetic approach). ${ }^{57,58}$ It might seem that carrying out the measurements over the powder-form sample could be a drawback of this approach, as this powder might not be representative of the microstructure of the membrane material. Indeed the issues of transport modelling when crystallite boundaries come into play were acknowledged to be a scientific challenge. In this study, we have clearly demonstrated that a gentle crushing of a perovskite sintered pellet preserves the microstructure of the solid, thus allowing a proper sampling for SSITKA experimentation.

We have presented a new methodology for evaluating the parameters needed to predict oxygen permeation through dense perovskite membranes. Rather than measuring the permeation flux over a membrane or a thin film, which is delicate and time-consuming to produce, measurements were carried out directly on the powder sample. The measurements consisted of a combination of TGA and isotopic oxygen exchange experiments. Both techniques are straightforward. In a TGA experiment, the sample is subjected to a temperature ramp going up or down under controlled oxygen flow. In the case study presented here, the kinetic and transport parameters for $\mathrm{Ba}_{0.5} \mathrm{Sr}_{0.5} \mathrm{Co}_{0.8} \mathrm{Fe}_{0.2} \mathrm{O}_{3-\delta}$ have been determined using this methodology. The approach retained can be used for reducible oxides that form oxygen vacancies. If necessary, more complicated oxygen non-stoichiometry thermodynamic models can be integrated into the approach, thus making it applicable to other MIECs. In a forthcoming study, we will show that by combining the microkinetic model with a hydrodynamic model (e.g., mass transfer) of the membrane configuration, the overall oxygen permeation can be correctly predicted under various conditions of pressure, temperature and membrane thickness.

\section{Conclusions}

We have described an original method based on a microkinetic approach for the estimation of the oxygen transport parameters from powder. This original approach has been first validated on the reference perovskite $\mathrm{La}_{0.6} \mathrm{Sr}_{0.4} \mathrm{Co}_{0.2} \mathrm{Fe}_{0.8} \mathrm{O}_{3-\delta}$ and then has been applied to $\mathrm{Ba}_{0.5} \mathrm{Sr}_{0.5} \mathrm{Co}_{0.8} \mathrm{Fe}_{0.2} \mathrm{O}_{3-\delta}$ powder. In contrast to previous IEDP, ERC and SSITKA studies that can determine the global exchange kinetic parameter, our microkinetic modelling approach allows the estimation of the forward and reverse kinetic rate, thereby accounting for the oxygen vacancy concentration. In addition, the self-diffusion rate coefficient was estimated at different oxygen partial pressures. This microkinetic approach that combines SSITKA and TGA measurements has the potential to significantly accelerate the characterization of oxygen transport in perovskites and related materials. In this study, the kinetic parameters were measured in a temperature window between $873 \mathrm{~K}$ and $1173 \mathrm{~K}$ and at two pressure conditions (21 $\mathrm{kPa}$ and $1 \mathrm{kPa}$ ) chosen for their appropriateness for simulating the semi-permeability of oxygen in a membrane in a process of oxygen separation from air. The values of the estimated parameters for oxygen adsorption and diffusion over $\mathrm{La}_{0.6} \mathrm{Sr}_{0.4} \mathrm{Co}_{0.2} \mathrm{Fe}_{0.8} \mathrm{O}_{3-\delta}$ in powder form are the same as those obtained by $\mathrm{Xu}$ and Thomson ${ }^{12}$ over the same perovskite but in a membrane configuration, implying that the approach shown here allows calculating the oxygen flux through the $\mathrm{La}_{0.6} \mathrm{Sr}_{0.4} \mathrm{Co}_{0.2} \mathrm{Fe}_{0.8} \mathrm{O}_{3-\delta}$ dense membrane. The simulation of the oxygen flux of the $\mathrm{Ba}_{0.5} \mathrm{Sr}_{0.5} \mathrm{Co}_{0.8} \mathrm{Fe}_{0.2} \mathrm{O}_{3-\delta}$ membrane using the estimated parameters obtained from the corresponding powder will be reported in an upcoming study.

\section{Symbol}

\begin{tabular}{|c|c|}
\hline$\delta$ & Oxygen non-stoichiometry $(-)$ \\
\hline$P_{\mathrm{O}_{2}}^{\prime}, P_{\mathrm{O}_{2}}^{\prime \prime}$ & $\begin{array}{l}\text { Partial pressure of oxygen on the rich side and } \\
\text { on the lean side, respectively (atm) }\end{array}$ \\
\hline $\mathrm{O}_{\mathrm{O}, \mathrm{s}}^{\times}, \mathrm{O}_{\mathrm{O}, \mathrm{b}}^{\times}$ & Surface oxygen and bulk oxygen, respectively $(-)$ \\
\hline $\mathrm{V}_{\mathrm{O}, \mathrm{s}}^{\bullet \bullet}, \mathrm{V}_{\mathrm{O}, \mathrm{b}}^{\bullet \bullet}$ & $\begin{array}{l}\text { Surface oxygen vacancies and bulk oxygen } \\
\text { vacancies, respectively (-) }\end{array}$ \\
\hline$h^{\circ}, h$ & Electron hole, electron hole concentration $(-)$ \\
\hline$\theta_{\mathrm{v}}, \theta_{16_{\mathrm{O}}}, \theta_{18_{\mathrm{O}}}$ & $\begin{array}{l}\text { Vacancy coverage, }{ }^{16} \mathrm{O} \text { coverage and }{ }^{18} \mathrm{O} \\
\text { coverage }(-)\end{array}$ \\
\hline$U$ & Superficial velocity $\left(\mathrm{cm} \mathrm{s}^{-1}\right)$ \\
\hline$J_{\mathrm{O}_{2}}$ & Oxygen flux $\left(\mathrm{mol} \mathrm{cm} \mathrm{cm}^{-2} \mathrm{~s}^{-1}\right)$ \\
\hline$D_{\mathrm{v}}$ & Diffusion of vacancies $\left(\mathrm{cm} \mathrm{s}^{-1}\right)$ \\
\hline$D^{*}$ & Self-diffusion of oxygen $\left(\mathrm{cm} \mathrm{s}^{-1}\right)$ \\
\hline$k$ & Surface rate coefficient $\left(\mathrm{cm} \mathrm{s}^{-1}\right)$ \\
\hline$k_{\mathrm{f}}$ & Forward adsorption rate coefficient $\left(\mathrm{Pa}^{-1} \mathrm{~s}^{-1}\right)$ \\
\hline$k_{\mathrm{f}}^{\circ}$ & $\begin{array}{l}\text { Forward adsorption pre exponential factor } \\
\left(\mathrm{Pa}^{-1} \mathrm{~S}^{-1}\right)\end{array}$ \\
\hline$k_{\mathrm{r}}$ & Reverse adsorption rate coefficient $\left(\mathrm{s}^{-1}\right)$ \\
\hline$k_{\mathrm{r}}^{\circ}$ & Reverse adsorption pre exponential factor $\left(\mathrm{s}^{-1}\right)$ \\
\hline$K$ & Langmuir constant $\left(\mathrm{Pa}^{-1}\right)$ \\
\hline$K^{\circ}$ & $\begin{array}{l}\text { Langmuir constant pre exponential factor } \\
\left(\mathrm{Pa}^{-1}\right)\end{array}$ \\
\hline
\end{tabular}




$\begin{array}{ll}S_{(\mathrm{BET})} & \text { BET surface area }\left(\mathrm{cm}^{2} \mathrm{~g}^{-1}\right) \\ \rho & \text { Solid density }\left(\mathrm{g} \mathrm{cm}^{-3}\right) \\ d_{\text {crys }} & \text { crystallite diameter }(\mathrm{cm}) \\ E_{\mathrm{f}}, E_{\mathrm{r}} & \text { Activation energy associated with the adsorp- } \\ & \text { tion or desorption, respectively }\left(\mathrm{kJ} \mathrm{mol}^{-1}\right) \\ \Delta H & \text { Oxygen adsorption enthalpy }\left(\mathrm{kJ} \mathrm{mol}^{-1}\right) \\ r & \text { Crystallite radius }(\mu \mathrm{m}) \\ L_{\mathrm{t}} & \text { Number of active sites }\left(\mathrm{mol} \mathrm{m}_{\mathrm{S}}{ }^{-3}\right) \\ \varepsilon_{\mathrm{b}} & \text { Inter-granular void space }\left(\mathrm{m}_{\mathrm{G}}{ }^{3} \mathrm{~m}_{\mathrm{R}}{ }^{-3}\right) \\ D_{\mathrm{e}} & \text { Effective axial diffusivity }\left(\mathrm{m}_{\mathrm{G}}{ }^{3} \mathrm{~m}_{\mathrm{R}}{ }^{-1} \mathrm{~S}^{-1}\right) \\ z & \text { Axial reactor coordinate }\left(\mathrm{m}_{\mathrm{R}}\right) \\ R & \text { Gas constant }\left(\mathrm{J} \mathrm{mol}{ }^{-1} \mathrm{~K}^{-1}\right) \\ T & \text { Absolute temperature }(\mathrm{K}) \\ v_{i j} & \text { Stoichiometric coefficient for } \mathrm{species} i \text { in } \\ r_{j} & \text { reaction } j(-) \\ V_{\mathrm{m}} & \text { Reaction rate of step } j\left(\mathrm{~s}^{-1}\right) \\ \sigma_{\mathrm{O}} & \text { Molar volume }\left(\mathrm{mol} \mathrm{cm}^{-3}\right) \\ F & \text { Oxygen conductivity }\left(\mathrm{S} \mathrm{cm}^{-1}\right)\end{array}$

\section{Acknowledgements}

The work leading to these results received funding from the European Union Seventh Framework Program FP7-NMP-2010Large-4, under grant agreement no 263007 (acronym CARENA).

\section{Notes and references}

1 A. Thursfield and I. S. Metcalfe, J. Mater. Chem., 2004, 14, 2475.

2 H. J. M. Bouwmeester, Catal. Today, 2003, 82, 141-150.

3 H. Dong, Z. Shao, G. Xiong, J. Tong, S. Sheng and W. Yang, Catal. Today, 2001, 67, 3-13.

4 J. E. Elshof, H. J. M. Bouwmeester and H. Verweij, Appl. Catal., 1995, 130, 195-212.

5 M. Rebeilleau-Dassonneville, S. Rosini, a. C. Van Veen, D. Farrusseng and C. Mirodatos, Catal. Today, 2005, 104, 131-137.

6 Z. Shao and S. M. Haile, Nature, 2004, 431, 170-173.

7 T. Schiestel, M. Kilgus, S. Peter, K. Caspary, H. Wang and J. Caro, J. Membr. Sci., 2005, 258, 1-4.

8 Cristina Tablet, Dense hollow fiber perovskite membranes for oxygen separation and partial oxidation of light hydrocarbons, PhD manuscript, University of Hannover, 2006.

9 Y. Teraoka, Z. Hua-Min, S. Furukawa and N. Yamazoe, Chem. Lett., 1985, 1743-1746.

10 J. Sunarso, S. Baumann, J. M. Serra, W. a. Meulenberg, S. Liu, Y. S. Lin and J. C. Diniz da Costa, J. Membr. Sci., 2008, 320, 13-41.

11 P. J. Gellings and H. J. M. Bouwmeester, Catal. Today, 2000, $58,1-53$.

12 S. J. Xu and W. J. Thomson, Chem. Eng. Sci., 1999, 54, 3839-3850.

13 J. B. Goodenough, Proc. R. Soc. London, 1984, 215-234.
14 S. Yakovlev, C.-Y. Yoo, S. Fang and H. J. M. Bouwmeester, Appl. Phys. Lett., 2010, 96, 254101-254103.

15 E. Bucher, A. Egger, P. Ried, W. Sitte and P. Holtappels, Solid State Ionics, 2008, 179, 1032-1035.

16 P. F. Haworth, S. Smart, J. M. Serra and J. C. Diniz da Costa, Phys. Chem. Chem. Phys., 2012, 14, 9104-9111.

17 C. Ftikos, S. Carter and B. C. H. Steele, J. Eur. Ceram. Soc., 1993, 12, 79-86.

18 R. A. De Souza, J. A. Kilner and B. C. H. Steele, Solid State Ionics, 1995, 77, 180-184.

19 T. Kawada, T. Horita, N. Sakai, H. Yokokawa and M. Dokiya, Solid State Ionics, 1995, 79, 201-207.

20 M. Sahibzada, W. Morton, A. Hartley, D. Mantzavinos and I. S. Metcalfe, Solid State Ionics, 2000, 137, 991-996.

21 J. Mürbe, A. Rechtenbach and J. Töpfer, Mater. Chem. Phys., 2008, 110, 426-433.

22 F. H. M. Dekker, A. Bliek, F. Kapteijn and J. A. Moulijn, Chem. Eng. Sci., 1995, 22, 3573-3580.

23 A. Manthiram, J. S. Swinnea, Z. T. Sui, H. Steinfink and J. B. Goodenough, J. Am. Chem. Soc., 1987, 109, 6667-6669.

24 G. K. Boreskov and V. S. Muzykantov, Ann. N. Y. Acad. Sci., 1973, 213, 137-160.

25 G. K. Boreskov, Discuss. Faraday Soc., 1966, 41, 263.

26 E. R. S. Winter, J. Chem. Soc. A, 1968, 2889-2902.

27 K. Klier, J. Novakova and P. Jiru, J. Catal., 1963, 484, 479-484.

28 G. B. Froment and K. B. Bischoff, Chemical Reactor Analysis and Design, John Wiley, New York, 1979.

29 A. Hindmarsh, A Systematized Collection of ODE Solvers, Elsevier, Amsterdam, 1983.

30 K. Levenberg, Q. Appl. Math., 1944, 11, 164-168.

31 D. W. Marquardt, J. Soc. Ind. Appl. Math., 1963, 11, 431-441.

32 G. F. Froment and L. H. Hosten, in Catalysis Science and Technology, ed. J. R. Anderson and M. Boudart, Springer Verlag, Berlin, 1981.

33 L. Rørmark, K. Wiik and T. Grande, J. Mater. Chem., 2002, 12, 1058-1067.

34 R. Kriegel, R. Kircheisen and J. Töpfer, Solid State Ionics, 2010, 181, 64-70.

35 S. Mcintosh, J. F. Vente, W. G. Haije, D. H. A. Blank and H. J. M. Bouwmeester, Solid State Ionics, 2006, 177, 1737-1742.

36 Y. Orikasa, T. Ina, T. Nakao, A. Mineshige, K. Amezawa, M. Oishi, H. Arai, Z. Ogumi and Y. Uchimoto, Phys. Chem. Chem. Phys., 2011, 13, 16637-16643.

37 M. H. R. Lankhorst, J. E. Elshof, T. La and S. Mo, J. Solid State Chem., 1997, 310, 302-310.

38 D. N. Mueller, R. A. De Souza, J. Brendt, D. Samuelis and M. Martin, J. Mater. Chem., 2009, 19, 1960.

39 S. Svarcova, K. Wiik, J. Tolchard, H. J. M. Bouwmeester and T. Grande, Solid State Ionics, 2008, 178, 1787-1791.

40 Z. Shao, W. Yang, Y. Cong, H. Dong, J. Tong and G. Xiong, J. Membr. Sci., 2000, 172, 177-188.

41 G. Carini II, H. U. Anderson, D. M. Sparlin and M. M. Nasrallah, Solid State Ionics, 1991, 49, 233-243.

42 J. Mizusaki, S. Yamauchi, K. Fueki and A. Ishikawa, Solid State Ionics, 1984, 12, 119-124. 
43 J.-I. Jung, S. T. Misture and D. D. Edwards, Solid State Ionics, 2012, 206, 50-56.

44 Z. Yang and Y. S. Lin, Solid State Ionics, 2002, 150, 245-254.

45 E. A. Kotomin, Y. A. Mastrikov, M. M. Kuklja, R. Merkle, A. Roytburd and J. Maier, Solid State Ionics, 2011, 188, 1-5.

46 A. Berenov, A. Atkinson, J. Kilner, M. Ananyev, V. Eremin, N. Porotnikova, A. Farlenkov, E. Kurumchin, H. J. M. Bouwmeester, E. Bucher and W. Sitte, Solid State Ionics, 2014, 268, 102-109.

47 D. Chen and Z. Shao, Int. J. Hydrogen Energy, 2011, 36, 6948-6956.

48 T. Ishigaki, S. Yamauchi, K. Kishio, J. Mizusaki and K. Fueki, J. Solid State Chem., 1988, 187, 179-187.

49 H. Ullmann, N. Trofimenko, F. Tietz, D. Stöver and a. Ahmad-Khanlou, Solid State Ionics, 2000, 138, 79-90.
50 L. Wang, R. Merkle, J. Maier, T. Acartürk and U. Starke, Appl. Phys. Lett., 2009, 94, 071908.

51 J. Serra and V. Vert, Catal. Today, 2011, 159, 47-54.

52 S. L. Shannon and J. G. Goodwin, Chem. Rev., 1995, 95, 677-695.

53 R. A. De Souza and J. A. Kilner, Solid State Ionics, 1998, 106, 175-187.

54 R. a. De Souza and M. Martin, Phys. Chem. Chem. Phys., 2008, 10, 2356-2367.

55 S. Carter, A. Selcuk, R. J. Chater, J. Kajda, J. A. Kilner and B. C. H. Steele, Solid State Ionics, 1992, 56, 597-605.

56 R. H. Nibbelke, J. Scheerova, M. H. J. M. De Croon and G. B. Marin, J. Catal., 1995, 156, 106-119.

57 J. Maier, Solid State Ionics, 1998, 112, 197-228.

58 J. A. Dumesic, D. Rudd, L. M. Aparicio, J. E. Rekoske and A. A. Trevino, The Microkinetic Analysis of Catalysis reaction, Washington D.C., 1993. 